\title{
Potensi dan Pengelolaan Ekowisata di Bendungan Karangkates Perum Jasa Tirta 1 Malang
}

\author{
Awan Setia Dharmawan \\ Prodi Sosiologi, Fakultas Ilmu Sosial dan Ilmu Politik, Universitas Muhammadiyah Malang, Indonesia \\ Email: setiadharmawan@umm.ac.id
}

\begin{abstract}
Indonesia has natural environment that is not far behind other countries, therefore the current trend is to utilize the potential of nature to become one of the bases for tourism. Ecotourism is a combination of industrial interests and environmentalists, with the hope of economic growth on the basis of environmental sustainability. But we have to be careful, if the economic factor is in contact with nature, then what will emerge is an anthropocentrism attitude. Through the very diverse potential of natural resources and the environment in Indonesia, the hope is that it will attract many tourists to come, this also has an impact on development. This study aims to determine the potential for ecotourism owned by the Karangkates Dam which is managed by Perum Jasa Tirta 1, which will specifically look at the aspects of tourism potential, environmental potential and potential for biodiversity. This study uses a qualitative method with case study which aims to describe the potential of ecotourism and analyze how ecotourism management is owned by the Karangkates Dam through the perspectives of stakeholders and tourists..
\end{abstract}

Keywords: Ecotourism; Environmental Sustainability; Management; Potention.

\begin{abstract}
Abstrak
Indonesia memiliki keindahan alam yang tidak kalah jauh dengan negara-negara yang lain, maka dari itu trend saat ini adalah memanfaatkan potensi alam untuk menjadi salah satu basis dari pariwisata. Ekowisata merupakan perpaduan antara kepentingan industri dengan pencinta lingkungan, dengan harapan bertumbuhnya perekonomian dengan basis environment sustainability. Tapi kita harus hati-hati, apabila faktor ekonomi sudah bersinggungan dengan alam, maka yang akan muncul adalah sikap antroposentrism.Melalui potensi sumber daya alam dan lingkungan yang sangat beragam di Indonesia, harapannya akan menarik banyak wisatawan untuk datang , hal ini juga berdampak pada pengembangan perekonomian di daerah setempat.Penelitian ini bertujuan untuk mengetahui potensi ekowisata yang dimiliki oleh Bendungan Karangkates yang dikelola oleh Perum Jasa Tirta 1, yang khususnya akan melihat dari aspek potensi wisata,potensi lingkungan dan potensi keberagaman hayati. Penelitian ini menggunakan metode kualitatif dengan analisis deskriptif, yang bertujuan untuk menggambarkan potensi ekowisata yang dimiliki dan menganalisa bagaimana pengelolaan ekowisata yang dimiliki oleh bendungan karangkates melalui perspektif stakeholders dan wisatawan.
\end{abstract}

Kata Kunci: Ekowisata; Environmental Sustainability; Potensi; Pengelolaan.

\section{A. PENDAHULUAN}

Berdasarkan laporan yang dikeluarkan World Tourism Organization (WTO), menunjukkan adanya beberapa kecenderungan dan perkembangan baru dalam dunia kepariwisataan yang mulai muncul pada tahun 1990- an. Dengan adanya kecenderungan masyarakat global, regional dan nasional untuk kembali ke alam (back to nature) (Arida, 2017), maka minat masyarakat untuk berwisata ke tempat-tempat yang masih alami semakin besar.) 
Ekowisata merupakan sebuah konsep yang mengkombinasikan kepentingan industri kepariwisataan dengan para pecinta lingkungan, sebuah kondisi yang menyebabkan terciptanya partnership dari kedua komponen tersebut, para pecinta lingkungan berasumsi bahwa kegiatan konservasi alam akan berhasil apabila bekerja sama dengan masyarakat lokal setempat. Maka konsep mengenai kebersamaan dalam menjaga alam atau menanamkan nilai konservasi lingkungan menjadi dasar atau basis dari ekowisata sendiri.

Dari sudut pandang industri pariwisata, ekowisata dipandang sebagai sebuah alternatif baru yang bisa memberikan daya tarik tersendiri terhadap para wisatawan.Saat ini memang cenderung proses perkembangan pariwisata di Indonesia menuju pada pariwisata berbasis

Artificial Intelligence atau kecerdasan buatan, yang dimana pengunjung hanya menikmati hiburan yang berbasis dunia simulasi, berkembangnya teknologi juga pasti memberikan pengaruh terhadap segala bentuk kehidupan, hingga kepada kebutuhan rekreasi masyarakat juga menerima dampak dari berkembangnya teknologi tersebut.

Maka dari itu konsep ekowisata datang sebagai jalan keluar yang baru apabila masyarakat mulai merasa jenuh dengan banyaknya ruang simulasi yang berkembang di dunia pariwisata itu sendiri. Konsep ekowisata pertama kali didengungkan pada konferensi tahunan ke 40 asosiasi perjalanan Asia Pasifik (PATA) oleh presiden WWF (Agribisnis, Pertanian, \& Widyagama, 2012),

Ekowisata pada saat ini menjadi aktivitas ekonomi yang sangat penting yang memberikan kesempatan kepada wisatawan untuk mendapatkan pengalaman mengenai pentingnya memahamai lingkungan sebagai suatu realitas yang tidak bisa kita pisahkan dari setiap perilaku individu, pentingnya konservasi lingkungan,konservasi mengenai keanekaragaman hayati dan yang tidak kalah penting adalah bagaimana memberikan pengetahuan baru mengenai budaya-budaya lokal yang berada disetiap daerah di Indoensia terutama.Selain itu keuntungan ekonomi juga memberikan dampak terhadap masyarakat yang tinggal di sekitar lokasi ekowisata.

Ekowisata dikatakan mempunyai nilai penting terhadap konservasi melalui hal berikut:

1. Memberikan nilai ekonomi bagi daerah yang mempunyai tujuan kegiatan konservasi pada daerah yang dilindungi.

2. Memberikan nilai ekonomi yang dapat digunakan untuk program konservasi.

3. Menimbulkan pendapatan baik langsung maupun tidak langsung kepada masyarakat sekitar.

4. Dapat mengembangkan konstituen yang mendukung konservasi ditingkat lokal, nasional, dan internasional.

5. Mendorong pemanfaatab sumber daya alam secara berkelanjutan.

6. Mengurangi ancaman terhadap keanekaragaman hayati yang terdapat di kawasan ekowisata tersebut.

Kegiatan ekowisata memang bisa memberikan dampak terhadap konservasi lingkungan dan menjaga keanekaragaman hayati yang dimiliki oleh daerah tersebut, secara tidak langsung penanaman nilai mengenai menghargai alam, menjaga kelestarian alam, dan pentingnya saling menjaga dan menghormati alam akan emmberikan dampak yang positif terhadap edukasi wisatawan mengenai pentingya sustainable environment.

Biasanya kegiatan ekowisata berada didaerah tropis yang mempunyai keanekaragaman hayati yang tinggi dan banyak flora dan fauna yang bersifat endemik, sehingga kondisi tersebut rentan terhadap perubahan yang ada. Dari sisi nilai tambah ekowisata, ada kemungkinan dalam impelemntasi program tersebut apabila tidak direncanakan dengan baik maka akan sebaliknya yang asalnya mendukung terhadap kelestarian lingkungan hidup malah mendorong terjadinya kerusakan lingkungan hidup di daerah tersebut. 
Oleh karena itu dalam penghembangan ekowisata perlu adanya rencana pengelolaan yang mengacu kepada tujuan utama awalnya yaitu mendorong dilakukannya konservasi lingkungan. Maka dari itu urgensi mengenai memperbanyak tempat yang bisa digunakan untuk ekowisata sekaligus menjadi edukasi dan perlindungan terhadap flora dan fauna yang ada didalamnya menjadi penting, karena kedepan dengan berkembangnya teknologi dan perubahan yang masih belum bisa di prediksi, keberadaan dan eksistensi lingkungan menjadi rentan akan eksploitasi. Ekspolitasi, pencemaran, pemburuaan hewan liar masih akan sering terdengar hingga kesadaran lingkungan yang salah satunya melalui proses edukasi menjadi poin penting.menurut (Butarbutar \& Soemarno, 2013) .

Terdapat beberapa komponen agar kegiatan ekowisata berjalan dengan baik dan berkelanjutan, yaitu keterkaitan antara stakeholders, tourismindusty, tourist, localcommunity, pemerintah, non pemerintah dan peneliti.

\section{B. KAJIAN PUSTAKA}

Vishwanatha \& Chandrashekara (2014), menjelaskan bagaimana dampak ekowisata terhadap lingkungan khususnya di daerah Kodagu, dalam hasil risetnya berbicara terkait dengan dampak positif dan negative keberadaan ekowisata, karena Kodagu sendiri merupakan daerah yang kaya akan flora dan fauna.(Ramadoss, 2010) juga melakukan penelitian terkait dengan konservasi keanekaragaman hayati untuk menuju pembangunan berkelanjutan, karena melalui pendidikan konservasi lingkungan tentunya akan membentuk ketahanan terhadap lingkungan itu sendiri.

K. Bricker (2014) menjelaskan bahwa kata kunci ekowisata adalah Being Green is Profitable, dalam kajian ini untuk menuju keberlangsungan keadaan keanekaragaman hayati dan perkembangan ekowisata yang semakin meluas tentunya akan membuat para pengusaha untuk lebih melihat aspek pengelolaan dan konservasi. Pola relasi ekowisata dengan local people, masyarakat local tentunya memiliki pengetahuan yang lebih daripada masyarakat pendatang atau pebisnis yang ingin membuka bisnis ekowisata, ekadaan alam dan bagaimana kenakeragaman hayati tentunya menjadi poin utama dalam konsep ekowisata, selain konservasi, edukasi, dan community based (K. S. Bricker, 2014; Manu \& Kuuder, 2012).

Pellis (2019) menjelaskan tidak menutup kemungkinan akan terjadinya konflik pada saat proses ekowisata ini, dalam tulisnya dijelaskan bahwa dalam kmonteks ekowisata konflik bisa muncul apabila realisasi ekowisata kurang bisa berjalan sesuai rencana, tidak menekankan terhadap partisipasi masyarakat lokal. (Wall, 1997) studi ini menekankan apakah ekowisata dapat berjalan secara berkala dengan baik? dan dijelaskan bahwa ekowisata disuatu momen akan berjalan dengan baik asalkan manajemen,pengelolaan, dan bagaimana daya Tarik yang disuguhkan dalam arena ekowisata.

\section{METODE PENELITIAN}

Penelitian ini menggunakan pendekatan kualitatif dengan menggunakan jenis penelitian studi kasus. Studi kasus disini dibatasi oleh waktu dan aktivitas (Creswell,2014). Yin (2011) menjelaskan secara umum studi kasus merupakan strategi yang cocok bila pokok pertanyaan penelitian berkenaan dengan bagaimana dan mengapa.

Ada 3 langkah dasar dalam menggunakan studi kasus, pertama adalah pengumpulan data, analisis, dan menulis. Hal pertama yang harus diingat tentang penggunaan studi kasus adalah bahwa kasus ini harus memiliki masalah bagi para peneliti untu menemukan jalan pemecahan masalahnya (Bungin, 2011).

\section{HASIL DAN PEMBAHASAN}


Dalam bagian ini peneliti akan terfokus kepada bagaimana menjawab 2 rumusan masalah yang disajikan pada penelitian ini, yaitu yang pertama Apa Potensi Ekowisata yang dimiliki oleh Bendungan Karangkates?Bagaimana pengembangan ekowisata yang dimiliki oleh Bendungan karangkates?.

Bendungan karangkates atau bisa juga disebut dengan bendungan Sutami memiliki 2 lokasi yang berbeda dalam pengelolaan wisatanya, yang pertama berada di daerah bendungan Sutami dan bendungan lahor, pada wisata bendungan sutami terdapat wahana berupa wisata kolam renang dan penginapan, sedangkan pada bendungan lahor terdapat juga resort berupa penginapan, spot selfie, camping ground, dan kedua lokasi wisata tersebut dibangun mulai tahun 2002.

Sejalan dengan apa potensi ekowisata yang dimiliki oleh Bendunga Karangkates, tentunya dengan wilayah yang luas dan bagaimana pengelolaan yang saat ini hanya terfokus pada pengelolaan air bendungan, maka ada beberapa potensi ekowisata yang kurang atau belum disentuh oleh pihak pengelola, yaitu pihak Perum Jasa Tirta 1, seperti halnya dengan bagaimana dukungan masyarakat dan wisatawan yang memang juga memberikan masukan terkait dengan bagaimana pengembangan ekowisata kedepan yang bisa digunakan sebagai acuan proses pembangunan ekowisata yang memang saat ini keberadaan ekowisata yang sangat dibutuhkan, karena sudah banyak sekali wisata-wisata yang berlandaskan artificial seperti banyaknya wahana wahana dengan kecanggihan tekhnologi didalamnya, tetapi bagaimana melihat bahwa alam pun juga memiliki potensi untuk pengembangan wisata berbasis ekologis.

Pengembangan potensi ekowisata selain memiliki lahan yang luas, tentunya pemanfaatan bagaimana wisata air bisa dikembangkan disana seperti banana boat, jet ski, dan perahu bebek bisa menjadi daya tarik tersendiri dari wisatawan ataupun pengunjungyang sejatinya hanya lewat saja karena bendungan karangkates ini merupakan sebagai jalan alternative dari Kabupaten Malang menuju ke Blitar.

Dalam membahas terkait dengan ekowisata sendiri menurut Fennel $(1991,22)$ disebutkan bahwa ada kerangka khusus dalam melihat perkembangan ekowisata sendiri, terdapat kaitan dalam melihat sumberdaya kegiatan wisata itu sendiri, yang pertama dalam konteks pelayanan industry, terdapat 3 komponen didalamnya yaitu, tour operator, resource management, community development. Yang ketiganya terkait satu sama lain dalam konteks perkembangan ekowisata itu sendiri.

Selain itu dari kacamata pengunjung terdapat 3 komponen juga yang saling berkaitan yaitu, marketing, visitor management, visitor attitudes. Maka dari itu terkait dengan potensi ekowisata yang dimiliki oleh Perum Jasa Tirta 1 adalah, bagaimana lebih bisa memanfaatkan terkait luas lahan yang dimiliki untuk membuat model ekowisata yang baru, dalam hal ini kendala utama dalam pengelolaan ekowisata yang diamati oleh peneliti adalah, bagaimana letak bendungan karangkates yang menjadi penghubung antara Kabupaten Blitar dengan Kabupaten Malang, maka dari itu bendungan karangkates sebagian besar hanya berfungsi sebagai jalan alternative saja.

Melalui potensi luas lahan yang begitu luas dan tentunya dengan pengelolaan yang baru terkait potensi ekowisata yang akan muncul tentunya hal ini juga didukung oleh masyarakat sekitar, yang bisa digunakan sebagai instrument untuk memberikan sumbangsih terkait bagaimana kedepannya agar lebih baik lagi dalam pengelolaan baik ekowisata yang sudah ada dan potensi yang bisa dimiliki.

Dalam hal ini, kegiatan Ekowisata yang memang direncanakan baik dengan pihak pengelola yaitu PJT 1 bagian pariwisata tentunya juga sudah mempraktikan bagaimana kolaborasi antar stakeholders yang ada. Salah satunya adalah bank BRI. Yang memang menjadi wajib kolaborasi dalam mengurus atau melaksanakan kegiatan pemberdayaan masyarakat.

Hasil diskusi kami dengan pihak PJT pada tanggal 14 Desember 2020, ditemukan bahwa dalam kasus pelonjakan Covid-19 yang terjadi saat ini, tidak begitu mempengaruhi aktivitas masyarakat yang berlibur kesana. Karena bisa diketahui bendungan karangkates merupakan jalan pintas yang menghubungkan Kabupaten Malang dengan Kabupaten Blitar. Maka secara otomatis hanya sebagai lalu lalang masyarakat. 
Melalui potensi ekowisata yang diimiliki mulai wahana air hingga camping ground tentunya akan menarik animo masyarakat untuk berhenti dan menikmati wahana yang ada, tentu juga berdampak kepada keadaan peningkatan ekonomi para penjual yang berada di sekitar Bendungan Karangkates.

\section{Analisa Teori}

Dalam penelitian ini peneliti menggunakan teori environmentally based tourism palnning framework (Downing dalam Fennel, 2003). Yang dimana dialamnya terdapat 5 komponen untuk memandang bagaimana ekowisata yang berbasis lingkungan. Poin pertama Objectives, survey and assessment, evaluation,synthesis,proposals. Melalui kelima komponen teori tersebut maka dalam hal menganalisa potensi ekowisata yang dimiliki oleh PJT 1 dalam hal objektif melihat bahwa kepentingan apa yang dibawa dan akan disampaikan oleh pengelola dalam membangun ekowisata berbasis lingkungan. Hal tersebut tentunya berimbas dari model ekowisata yang akan dikelola oleh pihak PJT 1, karena sampai saat ini bentuk ekowisata yanga dan disana masih kurang ada daya tariknya pengunjung, terutama wisata yang berbasis lingkungan, berbeda dengan bentuk wisata yang sudah ada seperti kolam renang yang memang setiap harinya ramai pengunjung. Bahkan saat peneliti melakukan wawancara disana, dikatakan pada periode Covid-19 ini tingkat naiknya pengunjung yang berada disana cenderung naik.

Pertanyaan kritisnya adalah selera pengunjung saat ini apakah menyukai wisata berbasis artificial? atau wisata yang berbasis lingkungan dan berkelanjutan. Tentunya hal ini menjadi penilaian tersendiri dari pihat pengelola wisata khususnya Perum Jasa Tirta 1 pengelola waduk Karangkates.

Dalam hal lain setelah melalui penelitian ini bahwa diketahui potensi ekowisata yang dimiliki oleh pihak PJT 1 adalah memanfaatkan luas lahan khususnya untuk wisata air hingga camping ground, tentunya akan berdampak pada pendapatan dan sektor ekonomi yang akan didapatkan, (Sherman,Dixon dalam Fennel, 2009) menyatakan ada 5 model yang bisa diapatkan dari pihak pengelola wisata untuk mendapatkan keuntungan secara fiannsial, yang pertama user fees, concession fees, royalties, taxation, and donations.

Dalam konteks user fees merupakan cerminan dari kesediaan masyarakat untuk membayar, dalam artian pengunjung wisata disana diminta dana retribusi atau ticket setiap masuk ke wana ekowisata yang sudah ada, concenssion fees pendapatan yang berasal dari pihak pemerintah, tour guide, barang dan jasa, royalties merupakan pendapatan yang berfungsi untuk proses pengembangan dan pengelolaan ekowisata di PJT melalui penjualan souvenir dan merchandise yang tersedia disana, taxation pendapatan yang didapatkan dari hasil pajak, dan donations dalam hal ini wisatawan diminta kesediannya untuk menyumbang dana dalam upaya mengatasi masalah lokal (kekurangan sumber daya atau uang untuk spesies yang terancam punah).

Melalui ke 5 komponen tadi diharapkan pihak PJT 1 bisa memanfaatkan konsep yang ada untuk bisa direalisasikan di lapangan dalam mengelola baik potensi ekowisata yang sudah ada dan model wisata yang ada saat ini, karena hal ini bertumpuan pada sistem pengelolaan yang ada. Hal ini menjadi kata kunci agar model ekowisata yang sudah ada disana bisa berkelanjutan dan bukan hanya bertujuan untuk ekonomi semata tetapi ada tujuan untuk mengedukasi masyarakat dan pengunjung tentang pentingnya melestarikan dan menjaga alam.

\section{E. SIMPULAN}

Kesimpulan dari penelitian ini adalah untuk mengetahui potensi ekowisata yang dimiliki oleh Perum Jasa Tirta 1 sebagai induk pengelola bendungan Karangkates dan bagaimana cara mengelola dan pengembangan potensi ekowisata yang dimiliki oleh pihak PJT 1. Yang tentunya potensi ekowisata yang dimiliki yaitu menafaatkan luas lahan yang dimiliki bentuknya bisa lebih memperbanyak wahan air dan camping ground untuk memberikan eduksi dan mernangkan apa yang dikatakan oleh (Arida, 2017) yaitu 
back to nature. Sedangkan model pengembangan dan pengelolaan yang dimiliki tentunya pihak PJT 1 tidak bisa sendiri dalam menggarap ini melainkan harus bekerja sama dengan pihak-pihak terkait untuk betulbetul mengelola potensi ekowisata yang sudah ada dana kan direncakan kedepannya.

\section{DAFTAR REFERENSI}

Agribisnis, P. S., Pertanian, F., \& Widyagama, U. (2012). Ekowisata. 1-17.

Arida, I. N. S. (2017). Ekowisata: Pengembangan, Partisipasi Lokal, dan Tantangan. In Cakra Press.

Bricker, K. (2014). The International Ecotourism Society. The International Ecotourism Society, 1, $1-10$.

Bricker, K. S. (2014). Trends and issues for Ecotourism and Sustainable Development. What Is Ecotourism, 1-43. Retrieved from https://www.ecotourism.org/

Butarbutar, R., \& Soemarno, S. (2013). Environmental Effects Of Ecotourism In Indonesia. Journal of Indonesian Tourism and Development Studies, 1(3), 97-107. https://doi.org/10.21776/ub.jitode.2013.001.03.01

Bungin.B.2008.penelitian kualitatif.Jakarta.Kencana Prenada Media Group

Creswell, J. 2013. Research design pendekatan kualitatif,kuantitatif, dan mix method.Yogyakarta. Pustaka Pelajar

Fennell, D. A. (n.d.). Ecotourism, second edition.

Manu, I., \& Kuuder, W. C.-J. (2012). Community-Based Ecotourism and Livelihood Enhancement in Sirigu, Ghana. International Journal of Humanities and Social Science, 2(18), 97-108.

Pellis, A. (2019). Reality effects of conflict avoidance in rewilding and ecotourism practices-the case of Western Iberia. Journal of Ecotourism, 18(4), 316-331. https://doi.org/10.1080/14724049.2019.1579824

Ramadoss, A. (2010). Biodiversity Conservation through Environmental Education for Sustainable Development - A Case Study from Puducherry, India. International Electronic Journal of Environmental Education, 1(2). https://doi.org/10.18497/iejee-green.99495

Vishwanatha, S., \& Chandrashekara, B. (2014). A Study on the Environmental Impacts of Ecotourism in Kodagu District, Karnataka. American Journal of Research Communication, 2(4), 256265.

Wall, G. (1997). Is Ecotourism Sustainable. Environmental Management, 483-491.

Yin.K.R.2011.Studi Kasus design,dan metode. Jakarta. PT Rajagrafindo Persada 